\title{
APPROACHES FOR FOREST BIOMASS ESTIMATION AND MAPPING IN CANADA
}

\author{
R.J. Hall', R.S. Skakun ${ }^{1}$, A. Beaudoin ${ }^{2}$, M.A. Wulder ${ }^{3}$, E.J. Arsenault ${ }^{1}$, P.Y. Bernier ${ }^{2}$, \\ L. Guindon ${ }^{2}$, J.E. Luther ${ }^{4}$, M.D. Gillis ${ }^{3}$ \\ Natural Resources Canada, Canadian Forest Service \\ ${ }^{1}$ Northern Forestry Centre, 5320 - 122 Street, Edmonton, AB, T6H 3S5 \\ ${ }^{2}$ Laurentian Forestry Centre, 1055 du P.E.P.S., QC, G1V 4C7 \\ ${ }^{3}$ Pacific Forestry Centre, 506 West Burnside Road, Victoria, BC, V8Z 1M5 \\ ${ }^{4}$ Atlantic Forestry Centre, 20 University Drive, Corner Brook, NL, A2H 6P9
}

\begin{abstract}
Knowledge of forest biomass is necessary for reporting on the state of Canada's forests. It is also an indicator of carbon that enables insights on the interaction between forests and the atmosphere. Forest biomass information has largely been aspatial and derived using plot estimates from Canada's National Forest Inventory. Provincial and territorial governments and private industrial organizations have broadened the diversity of information needs and demand for methods that are more spatially explicit. These realities have resulted in a variety of data sources nested within four approaches that can be applied from local to national scales. Earth observation data contribute to each of these approaches to varying degrees and not all approaches result in large area biomass maps. This paper describes the approaches for biomass mapping in Canada, their synergism, and highlights their dynamic nature as new data sources and ongoing developments will continue to refine these approaches to estimate, map, and monitor forest biomass in Canada.
\end{abstract}

Index Terms - forest biomass, inventory, remote sensing, carbon, Canada

\section{INTRODUCTION}

Canada's land mass covers nearly a billion hectares in size, of which approximately $60 \%$ can be considered as ecosystems that support forests, but also contain lakes, wetlands, and vegetated but non-forested areas [19]. These forested ecosystems occur across broad geographic ranges, by both latitude and longitude, with different soil and climatic conditions that influence forest productivity and growth. Aside from environmental considerations, forests in Canada are also subject to differing management considerations ranging from industrial uses to conservation. The primary stewardship of Canada's forests rest with provincial and territorial agencies that have the constitutional authority related to the development, conservation and management of forest resources [5]. A key role of the Federal government regarding forestry in Canada is to enable and implement national reporting and participation in international monitoring and reporting activities to meet international obligations [10]. The federal government supports a national forest inventory in partnership with provincial and territorial resource agencies in order to meet these obligations [6].

Forest biomass provides an indicator of how much carbon exists in a forest ecosystem, and is thus, a variable that provides a primary insight on forest status and function [4]. Traditional forest inventories have been more focused on estimates of merchantable volume information. Relationships between merchantable volume and biomass components have been developed [3], and these form a linkage between traditional measures and approaches from which to estimate biomass.

Estimates of forest biomass are used to meet many information needs from estimates of carbon dioxide uptake from the atmosphere to the capacity for a given forested area to support bio-energy initiatives. Generating knowledge about biomass, however, requires dealing with issues of data availability, tree-to-stand scaling of allometric functions, and the spatial and temporal coverage of existing forest inventories, to name a few. To address the challenges of these varying information needs and data issues, at least four different approaches for biomass estimation and mapping have been developed in Canada. The purpose of this paper is to briefly describe these approaches and the underlying context that frames the rationale for their development.

\section{BIOMASS ESTIMATION AND MAPPING}

The four approaches for estimating and mapping forest biomass in Canada can be broadly categorized as:

a. National Forest Inventory;

b. Biomass from satellite land cover and inventory models; 
c. Multi-resolution / multi-sensor scaling; and

d. Statistical imputation of plot information

\subsection{National Forest Inventory}

Forest biomass is often estimated using allometric functions from inventory data as input [4]. The 1981 Canada's Forest Inventory (CanFI) was first employed to estimate biomass nationally from a compilation of provincial and territorial inventory data, and the estimates were reported on a $10 \mathrm{~km}$ by $10 \mathrm{~km}$ cell basis [2]. These estimates were subsequently updated using the CanFI 2001 database. While costeffective because it was based on existing data, this approach was limited by the variability among provinces in inventory frequency, intensity and standards and was therefore not conducive for monitoring [6]. The need to monitor change over time led to the creation of a new National Forest Inventory (NFI) that is comprised of a permanent monitoring framework of $2 \mathrm{~km}$ by $2 \mathrm{~km}$ photo plots on a $20 \mathrm{~km}$ by $20 \mathrm{~km}$ grid across the country [6]. The NFI is implemented in collaboration with provinces and territories. Satellite data are used to provide surrogate plot attribute data for photo plots for which aerial photo or ground plot information is not available [18]. Values of attributes at NFI photo plots are used to estimate merchantable volume from which aboveground biomass was derived [3], and mapped through an inverse-weighting spatial imputation technique to generate relatively large area polygon estimates.

All NFI plots are considered permanent and thus, are conducive for estimation of change through periodic remeasurement [18]. Remotely sensed data to assess change will contribute towards the establishment of the NFI as an operational, national inventory monitoring program for Canada. The NFI provides the official inventory information used in reporting on the extent, state, and sustainable use of Canada's forest [6].

\subsection{Biomass from satellite land cover maps and inventory models}

The Earth Observation for Sustainable Development of Forests (EOSD) project was established to create a circa year 2000, 23 class land cover map of the forested areas of Canada [19]. Over 480 Landsat 5 and 7 images were classified and mapped, and from which 630, 1:250,000 map product tiles were produced for open distribution. The NFI classification legend was used for labeling of forest and non-forest land cover. EOSD has provided direct, basic inventory information for the forested areas of Canada including areas at NFI plots for which field or aerial photobased inventory information was not available. As a result, EOSD is closely integrated with the NFI, and provides input information to Canada's carbon accounting initiative [19].
From an inventory perspective, due to the use of Landsat imagery as a base, EOSD only provides basic information about forest land cover composition and structure. Volume and aboveground biomass estimates were assigned to satellite derived forest land cover through a series of manipulations in which the first step was the imputation of stand height from look-up tables classified by forest vegetation land cover type, ecozone, site class, stand density and age class extracted from CanFI. The imputed stand height was used in inventory models to estimate total volume that were stratified by ecozone, forest type and density. The underlying data for these models were provincial and territorial permanent sample plot (PSP) and temporary sample plot (TSP) data sets that were compiled and used to generate model-based, volume to biomass conversion functions. Total and merchantable volumes were subsequently used as predictors of total aboveground biomass and biomass components that included stem wood, branch, bark and foliage [3]. Computer geoprocessing scripts were developed to generate a national aboveground biomass map tied to the EOSD land cover at a $25 \mathrm{~m}$ spatial resolution. These estimates were then aggregated to larger, coarser scale spatial units to ensure consistency with the more spatially coarse inputs of age from CanFI and climate. Based on an independent assessment at 6 regions spanning multiple ecological zones across Canada, this approach for mapping biomass is considered most reliable for cells 10,000 ha in size (with an average $r^{2}$ of 0.8 , with biases ranging from 7 to $57 \mathrm{t} / \mathrm{ha}$, that largely varies as a function of the biomass range present). While not suited for local or site specific information needs, this approach is a regional and national indicator of the relative magnitude and spatial distribution of biomass across the forested areas of Canada. These biomass estimates have been used at NFI photo plots that lack provincial or territorial inventory data.

\subsection{Multi-resolution/multi-sensor scaling}

Since the potential to use satellite data for mapping forest biomass is contingent upon the availability of in-situ inventory data, it follows that the approach to map biomass should match the currency and type of inventory data available. Previous attempts to map forest biomass over large areas without satellite data have been considered problematic, suggesting that the integration of satellite and in-situ inventory data would be preferable to either alone [7]. The fact that inventory data varies throughout Canada, however, provides the context for different approaches where one may be more optimal for application in one area than another. BioCLUST (Biomass from Cluster Labeling Using Structure and Type) [13] and BioSTRUCT (Biomass estimation from stand STRUCTure) [9] offer practical approaches when limited inventory coverage is available. Using stand level equations, biomass is estimated as a function of inventory stand height and crown closure and by 
the relationship to image spectral response variables. Although these approaches are similar by design in that they estimate biomass through stand structure, the method foundations and principal data sources are different. BioCLUST requires forest polygon inventories and applies biomass look-up tables to image clusters, whereas BioSTRUCT uses forest inventory plots and image spectral response data in a continuous variable modeling approach. A k-Nearest Neighbour (k-NN) imputation method has also been developed whereby biomass estimates are derived from point estimates at inventory plot locations derived from field or other spatial data sets. With $\mathrm{k}-\mathrm{NN}$, a biomass estimate at a given pixel location on an image is determined by the weighted average of the inventory biomass plots that fall within the k-nearest neighbours as defined by Euclidean distance in multispectral space [11]. In each of these methods, spatial maps of stand-level biomass can be generated when inventory data is integrated with Landsat satellite data.

For regions where forest inventory data is sparse or nonexistent, such as in northern Canada, a new approach was developed to generate surrogate biomass samples based on high spatial resolution imagery such as QuickBird. These samples serve as data inputs for subsequent scaling of biomass estimates to a Landsat Thematic Mapper image [1]. This approach, referred to as Biomass Shadow Fraction (BioSF), creates a biomass image map by modeling in-situ biomass estimates as a function of the ratio between the number of tree shadow pixels and the total number of pixels within a defined pixel window size on a QuickBird image [12]. These shadow fraction models are used to estimate and map stand structure and forest biomass across the entire high spatial resolution image where a given forest type such as conifer species occurs. The BioSF works well in open conifer stands with moss or lichen understories [12], and is not intended for use in more southern regions where larger stand densities tend to predominate. Other similar approaches are used to estimate forest structure and biomass in deciduous and mixedwood.

The production of surrogate biomass samples on high spatial resolution image data can be scaled to Landsat imagery for large area mapping. This was demonstrated in a study whereby 600 biomass surrogate samples were extracted from a biomass map using QuickBird image data that was subsequently scaled to a Landsat image using the $\mathrm{k}-\mathrm{NN}$ imputation method [8]. An advantage of the multisensor scaling procedure is the means by which a judicious sample of field plots can be derived from a QuickBird image and then scaled across a Landsat image. BioCLUST, BioSTRUCT and BioSF combined with k-NN are each considered methods that can be used to map biomass over large areas, but they are unsuited for mapping biomass nationally, as they are dependent on the type and availability of in-situ inventory (eg., plot, polygon) data available.

\subsection{Statistical imputation of plot information}

An approach based on a non-parametric k-NN imputation method driven by inventory and remote sensing data has proven to be efficient for national inventory purposes [14]. Moderate Resolution Imaging Spectroradiometer (MODIS) imagery at $250 \mathrm{~m}$ resolution offers global and frequent coverage capacity that can potentially serve as the basis for Canada's national level biomass mapping and monitoring needs. In particular, the repeat coverage of MODIS offers the possibility to generate annual updates of forest attributes. A statistical imputation technique for Canada is being developed whereby $\mathrm{k}-\mathrm{NN}$ imputation is applied to NFI photo-plots within the multi-spectral coverage of MODIS.

The province of Quebec $\left(1.7 \mathrm{M} \mathrm{km}{ }^{2}\right)$ is serving as a large pilot region covering a broad range of Canadian forest types. The sampling protocol includes randomly selecting NFI $2 \times 2 \mathrm{~km}$ photo plots along with its associated MODIS $250 \mathrm{~m}$ image pixels. A portion of the sample cells would be used to train the k-NN imputation algorithm with the remaining cells being retained for accuracy assessment. Independent regional biomass maps developed from different input data sources will also contribute to the accuracy assessment process. This approach is predicated upon the availability of yearly MODIS-derived land cover or change products using $250 \mathrm{~m}$ MODIS data. Both static and dynamic approaches for year-to-year biomass mapping based on MODIS-based land cover and change products, respectively, are currently being investigated, along with the influence of key k-NN parameters in driving the imputation and mapping process.

The proposed NFI-based, k-NN imputation and mapping approach could fulfill the need for an operational wall-to-wall and year-to-year biomass mapping method across Canada, considering its: 1) method simplicity and non-parametric approach, 2) flexibility to add environmental data that may improve biomass estimation (e.g., climate surfaces, topography, and vegetation land cover), and 3) cost effectiveness considering the expected level of accuracy compared to low cost of data acquisition and processing. This combination of NFI plots and MODIS imagery could provide an effective means from which to map and monitor forest biomass across Canada, along with a suite of related attributes such as forest composition, height, volume and productivity.

\section{DISCUSSION AND CONCLUSIONS}

In Canada, several approaches have been developed that result in point estimates or spatial maps of biomass. A common thread with these approaches is the integration of multiple sensors, in-situ data, and allometric functions. Synergistic approaches avoid limitations associated with using a single data source. Accordingly, there is no single 
approach that is considered optimal for estimation and mapping of forest biomass in Canada. The development of biomass-estimation tools is a very dynamic process and improvements will occur as new data sources or refinements in methods evolve.

The use of active remote sensing technologies such as LiDAR and RADAR has not been described in this communication. There has been a plethora of studies directed at evaluating the use of LiDAR for estimating forest structure, volume and biomass [17]. Similarly, spaceborne RADAR imagery at C- and L-band wavelengths has demonstrated potential to map these same attributes over sizeable regions of the boreal [16]. In this context, increased future use of LiDAR and RADAR technologies are anticipated for estimating and mapping forest biomass.

\section{REFERENCES}

[1] Beaudoin, A., R.A., Leboeuf, L. Guindon, R. Fournier, J.E. Luther, M.-C. Lambert. "Mapping of Canadian northern boreal forest biomass using QuickBird high spatial resolution imagery," pp. 66-70 in Proceedings FORESTSAT 2005: Operational Tools in Forestry Using Remote Sensing Techniques, 31 May - 1 June 2005, Borås, Sweden, 2005.

[2] Bonner, G.M., "Inventory of forest biomass in Canada," Canadian Forest Service, Hull, Quebec, Cat. No. FO42-80, 1985.

[3] Boudewyn, P., X. Song, S. Magnussen, and M.D. Gillis, Model-based, volume-to-biomass conversion for forested and vegetated land in Canada, Natural Resources Canada, Pacific Forestry Centre, Victoria, British Columbia, Inf. Rep. BC-X-411, 2007.

[4] Brown, S., "Measuring carbon in forests: current status and future challenges," Environ. Pollut. vol. 116, pp. 363-372, 2002.

[5] Canadian Council of Forest Ministers. Canada's Forest Strategy for 2008 and Beyond. Natural Resources Canada, Canadian Forest Service, Ottawa, Ont. 2008.

[6] Gillis, M.D., A.Y. Omule and T. Brierley, "Monitoring Canada's forests: the national forest inventory," For. Chron. vol. 81, pp. 214-221, 2005.

[7] Goetz, S.J., A. Baccini, N.T. Laporte, T. Johns, W. Walker, J. Kellndorfer, R.A. Houghton and M. Sun, "Mapping and monitoring carbon stocks with satellite observations: a comparison of methods," Carbon Balance Manage., vol. 4, pp. 1-7, 2009.

[8] Guindon, L., A. Beaudoin, A. Leboeuf, C.-H. Ung, J.E. Luther, S. Côté, and M.-C. Lambert, "Regional mapping of Canadian subarctic forest biomass using a scaling up method combining QuickBird and Landsat imagery," pp. 71-75 in Proceedings FORESTSAT 2005: Operational Tools in Forestry using Remote Sensing Techniques, 31 May - 1 June 2005, Borås, Sweden, 2005.
[9] Hall, R.J., R.S. Skakun, E.J. Arsenault, and B.S. Case, "Modeling forest stand structure attributes using Landsat ETM+ data: Application to mapping of aboveground biomass and stand volume," Forest Ecol. Manag. vol. 225, pp. 378-390, 2006.

[10] Kurz, W.A. and M.J. Apps, "Developing Canada's national forest carbon monitoring, accounting and reporting system to meet the reporting requirements of the Kyoto Protocol," Mitig. Adapt. Strat. Global Change vol. 11, pp. 33-43, 2006.

[11] Labrecque, S., R.A. Fournier, J.E. Luther, and D.E. Piercey, "A comparison of four methods to map forest biomass from Landsat-TM and inventory data in western Newfoundland," Forest Ecol. Manage. vol. 226, pp. 129-144, 2006.

[12] Leboeuf, A., A. Beaudoin, R. Fournier, L. Guindon, J. Luther, and M.-C. Lambert, "A shadow fraction method for mapping biomass of northern boreal black spruce forests using QuickBird imagery," Remote Sens. Environ. vol. 110, no. 4, pp. 488-500, 2007.

[13] Luther, J.E., R.A. Fournier, D.E. Piercey, L. Guindon, and R.J. Hall, "Biomass mapping using forest type and structure derived from Landsat TM imagery," Int. J. Appl. Earth Obs. vol. 8, pp 173-187, 2006.

[14] McRoberts, R.E. and E.O. Tomppo. "Remote sensing support for national forest inventories," Remote Sens. Environ. vol. 100: 412-419, 2007.

[15] Natural Resources Canada, The State of Canada's Forests, Natural Resources Canada, Ottawa, Ont., 2009.

[16] Wagner, W., A. Luckman, J. Vietmeier, K. Tansey, H. Balzter, C. Schmullius, M. Davidson, D. Gaveau, M. Gluck, T.L. Toan, S. Quegan, A. Shvidenko, A. Wiesmann, J.J. Yu, "Largescale mapping of boreal forest in Siberia using ERS tandem coherence and JERS backscatter data," Remote Sens. Environ., vol. 85, pp. 125-144, 2003.

[17] Wulder, M.A., C. W. Bater, N.C. Coops, T. Hilker, and J.C. White, "The role of LiDAR in sustainable forest management," For. Chron., vol. 84, no. 6, pp. 807-826, 2008a.

[18] Wulder, M.A., W.A. Kurz, and M. Gillis, "National level forest monitoring and modeling in Canada," Prog. Plann. vol. 61, pp. 365-381, 2004.

[19] Wulder, M.A., J.C. White, M. Cranny, R.J. Hall, J.E. Luther, A. Beaudoin, D.G. Goodenough, and J.A. Dechka, "Monitoring Canada's forests. Part 1: completion of the EOSD land cover project," Can. J. Remote Sensing, vol. 34, no. 6, pp. 549-562, 2008 b. 